\title{
Fomentando a pesquisa de economia experimental em universidades: a utilização de notas como incentivos não monetários ${ }^{\dagger}$
}

\author{
Felipe Wolk Teixeira* \\ Gisele de Mozzi**
}

\begin{abstract}
RESUMO - Neste estudo, é mostrada uma análise do uso de notas para estudantes como uma alternativa a incentivos monetários no estímulo à participação em pesquisas de economia experimental no Brasil. O alvo deste estudo foi um experimento com simulações de compra e venda de ações realizado com alunos de graduação da Universidade Federal de Santa Catarina. Foi observado um grau de interesse maior no grupo de alunos onde foram oferecidas notas em relação ao grupo sem essa remuneração. $O$ índice de abstenção foi também inferior nas atividades com notas. Acredita-se que os resultados obtidos sejam um indicador de que o uso de notas é uma opção de incentivo para a realização de atividades experimentais.
\end{abstract}

Palavras-chave: Incentivos. Notas. Economia experimental.

\section{INTRODUÇÃO}

O ramo de economia experimental consiste na aproximação de situações reais em ambientes controlados, de forma a permitir maior isolação das variáveis de estudo, reduzindo ruídos indesejados pelo pesquisador. Estes experimentos não apenas ajudam a desenvolver novos paradigmas teóricos pertinentes, como também têm se mostrado potenciais ferramentas de ensino em universidades, um catalisador no processo pedagógico. Estas evidências aparecem em Emerson e Taylor (2004) e Durham, McKinnon e Schulman (2007).

A internet também age como ator de disseminação; um exemplo disso é a proposta do EconPort ${ }^{1}$, onde é possível executar online diversos experimentos pré-fabricados, ou com pequenas modificações.

No Brasil, o desenvolvimento da economia experimental ainda está em estágios iniciais, contando com um baixo número de laboratórios de pesquisa, como o Centro de Economia Experimental da Fundação Getulio Vargas². Possíveis razões para isso podem ser os custos de desenvolvimento da economia experimental: (A) capital físico, como a necessidade de labo† Os autores agradecem a Douglas Eduardo Turatti e Patrícia Vieira Abraham pelo auxílio prestado durante a realização das atividades no LabMec. O autor agradece o apoio da Capes através da bolsa de mestrado recebida durante a realização das atividades de coleta da pesquisa.

* Mestre em Economia pela Universidade Federal de Santa Catarina. É analista de planejamento, orçamento e gestão do IBGE. Endereço eletrônico: felkbr@gmail.com.

** Graduada em Psicologia pela Universidade do Sul de Santa Catarina. Endereço eletrônico: gisele.dmozzi@gmail. com.

1 Disponível em: <http://www.econport.org/>.

2 Mais informações disponíveis no endereço: <http://epge.fgv.br/cee/economia-experimental.jsp>. 
rátorios de informática bem equipados; e (B) remuneração aos participantes do experimento.

Visando redução do primeiro custo, podem ser elaboradas adaptações não informátizadas, hand-run, como os aplicados em salas de aula 3 . Já para o segundo, há a possibilidade de criação de incentivos não monetários aos participantes.

Este estudo tenta fornecer avanços na área de incentivos na forma de bonificações em notas de aulas para participação em experimentos de economia. Buscou-se aqui aplicar incentivos em atividades de finanças comportamentais, mais especificamente a simulação de um mercado de ações.

\section{ECONOMIA EXPERIMENTAL}

Certos aspectos da teoria econômica são mais facilmente estudados de forma experimental. A facilidade surge devido a capacidade de se isolar as variáveis, permitindo um grau maior de controle sobre cada fator relevante ao evento estudado. Esses experimentos convergem para um objetivo: a esperança de que os resultados coletados sejam capazes de gerar modelagens mais próximas aos cenários reais.

Jackstadt, Johnson e Wilson (2007) levantaram as principais barreiras à aplicação de experimentos como ferramenta de ensino de economia apontadas por professores do ensino primário e secundário norte-americano (Tabela 1). A falta de recursos para incentivos aparece como a principal barreira. Outro destaque é a falta de infraestrutura, representado pela falta de projetores e laboratórios de informática.

TABELA 1 - BARREIRAS À ADOÇÃO DE EXPERIMENTOS

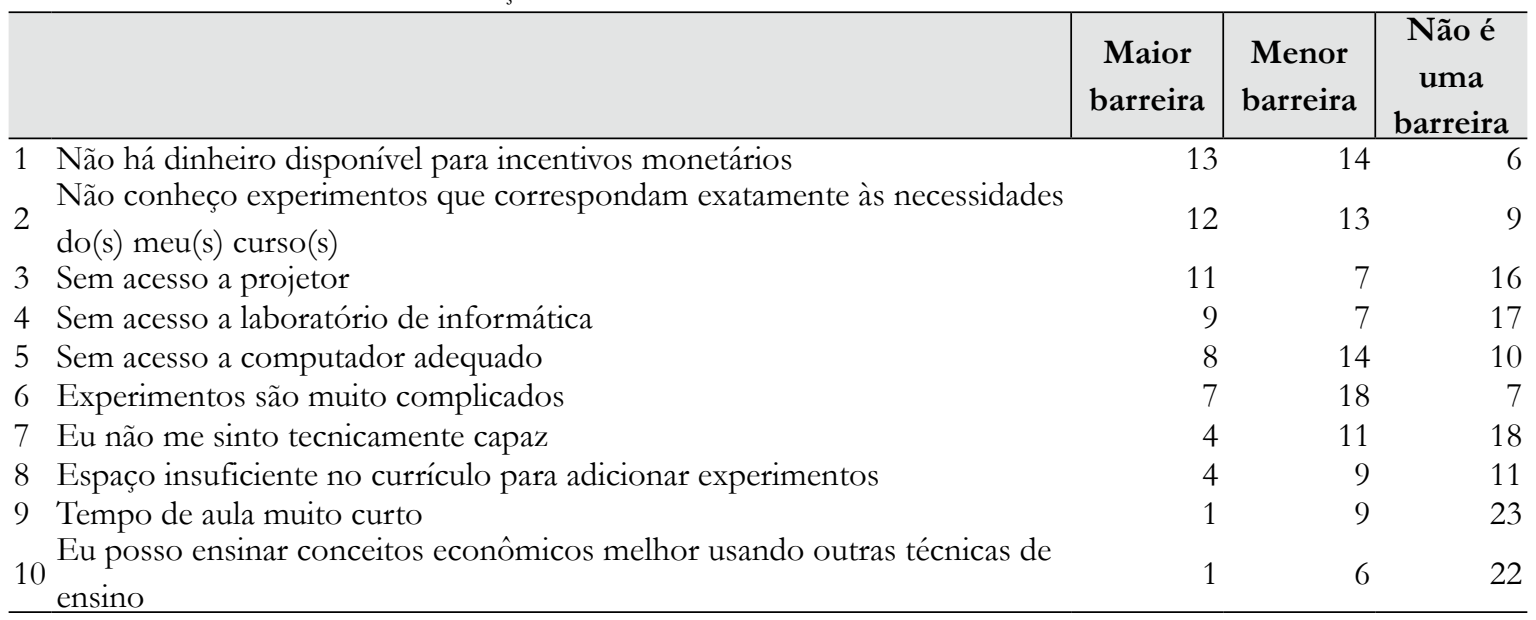

FONTE: Jackstadt, Johnson e Wilson (2007).

3 Brauer (1994) elaborou uma coletânea de jogos não computadorizados, divididos em diversas categorias, facilitando o acesso e modificação para aplicações específicas; o contéudo conta com constantes atualizações online por Brauer e Delemeester, disponível em: <http://www.marietta.edu/ delemeeg/games/>. 
Outro aspecto de fundamental importância é a seleção da população ou amostra do estudo. De forma prática, é interessante limitar o pool de estudo a um de relevância para os pesquisadores: os próprios estudantes universitários; espera-se que sua maior participação em experimentos incorra em custos menores quando comparados a pools externos.

Ainda assim, é necessário encontrar um vínculo entre eles, uma variável que sirva como incentivo para o ato de participar de experimentos. Nesse caso, a oferta de notas pode vir a servir como incentivo, visto que é o principal meio utilizado nas instituições de ensino nacionais para avaliar os estudantes. Grove e Wasserman (2006) mostram inclusive que a maior oferta de incentivos em notas pode melhorar a performance dos alunos.

Nesse estudo, a utilização de notas deve ser vista em um âmbito macro: apesar do valor percebido por cada aluno referente às notas ser heterogêneo, busca-se apenas uma aproximação de um sistema de remuneração funcional para estudantes em um ambiente acadêmico. A utilização de notas como mecanismo de incentivos já vem sendo utilizada em experimentos em economia, como em Bergstrom e Miller (1999).

\section{METODOLOGIA}

As atividades foram realizadas no Laboratório de Mercado de Capitais $\left(\mathrm{LabMec}^{4}\right)$, da Universidade Federal de Santa Catarina, entre os meses de agosto a outubro de 2008, com a participação de 83 estudantes dos cursos de graduação em Administração, Ciências Contábeis e Ciências Econômicas da Universidade Federal de Santa Catarina.

Eles transacionaram, em duplas, três diferentes tipos de ações simultaneamente. As negociações foram feitas na forma de double auction, coletando-se os lances de compra e venda para cada tipo de ação ${ }^{5}$. A simulação teve duração média de uma hora e quarenta minutos. $\mathrm{O}$ resultado final era divulgado posteriormente para os participantes e a remuneração era feita de acordo com o sistema acordado com o professor da disciplina, explicitado a seguir.

Foram realizadas sete atividades ao todo: três sem remuneração e quatro atividades com remuneração na forma de notas. O sistema utilizado foi um misto de remuneração por ranking e fixa (um mínimo foi oferecido aos participantes). O desempenho das duplas foi mensurado de acordo com a soma dos recursos totais ao término da atividade, com as duplas ordenadas de forma decrescente. Os pontos foram dados em uma das três avaliações do semestre de cada disciplina, de acordo com a distribuição da Tabela 2.

4 Ver: <http://labmec.ufsc.br/>.

5 As atividades foram realizadas de acordo com as normas éticas propostas pela APA - American Psychological Association. Maiores detalhes sobre a metodologia podem ser obtidos diretamente com os autores. 
TABELA 2 - PONTOS DISTRIBUÍDOS RELATIVOS AS NOTAS MÍNIMAS E MÁXIMAS DA DISCIPLINA

FONTE: Elaborado pelos autores.

\begin{tabular}{l|r|r|r}
\hline Classificação & Pontos & \% da nota total & \% da nota para aprovação \\
\hline 1 & 1 & $3,33 \%$ & $5,56 \%$ \\
2 & 0,8 & $2,67 \%$ & $4,44 \%$ \\
3 & 0,7 & $2,33 \%$ & $3,89 \%$ \\
4 & 0,5 & $1,67 \%$ & $2,78 \%$ \\
5 & 0,4 & $1,33 \%$ & $2,22 \%$ \\
6 & 0,3 & $1,00 \%$ & $1,67 \%$ \\
\hline
\end{tabular}

A dupla melhor colocada recebeu 1 ponto em uma das 3 avaliações da disciplina, representando um total de 3,33\% do total da nota possível em um semestre letivo, e 5,56\% da nota necessária para obter aprovação na disciplina. Foi oferecido também um incentivo mínimo, tal que mesmo a última dupla recebeu 0,3 décimos, o equivalente a $1 \%$ do total da nota possível em um semestre e 1,67\% da nota mínima para aprovação.

\section{RESULTADOS}

O primeiro ponto a ser discutido é o grau de interesse dos alunos pela atividade proposta, medido pela simples razão entre total de alunos convidados e alunos que demonstraram interesse em participar. De um total de 240 alunos convidados, 129 se mostraram interessados; a proporção entre interessados e convidados foi de 53,75\% (Gráfico 1).

Notou-se maior interesse nas turmas onde foi oferecida remuneração na forma de notas: 58,33\% do grupo onde foi ofertada remuneração por notas se demonstrou interessado; no grupo onde não foi ofertada remuneração foi de 46,88\%. A diferença no grau de interesse é um indício de que as notas possam servir como mecanismo de remuneração.

Outro ponto interessante é o maior interesse por parte do grupo de turmas diurnas, um grau de interesse de 71,05\%, bastante elevado quando comparado aos 45,73\% do grupo de turmas do noturno. Esse interesse maior pode estar vinculado ao próprio diferencial de perfil dos alunos do diurno e noturno. Os alunos do noturno tendem a já estarem inseridos no mercado de trabalho, com regimes de trabalho de 30 a 40 horas semanais além do curso de graduação, mostrando-se menos propensos a participarem de atividades acadêmicas ${ }^{6}$.

6 Isso foi observado durante o convite para a atividade, de acordo com a flexibilidade demonstrada por cada turma. 
GRÁFICO 1 - GRAU DE INTERESSE POR AGRUPAMENTO

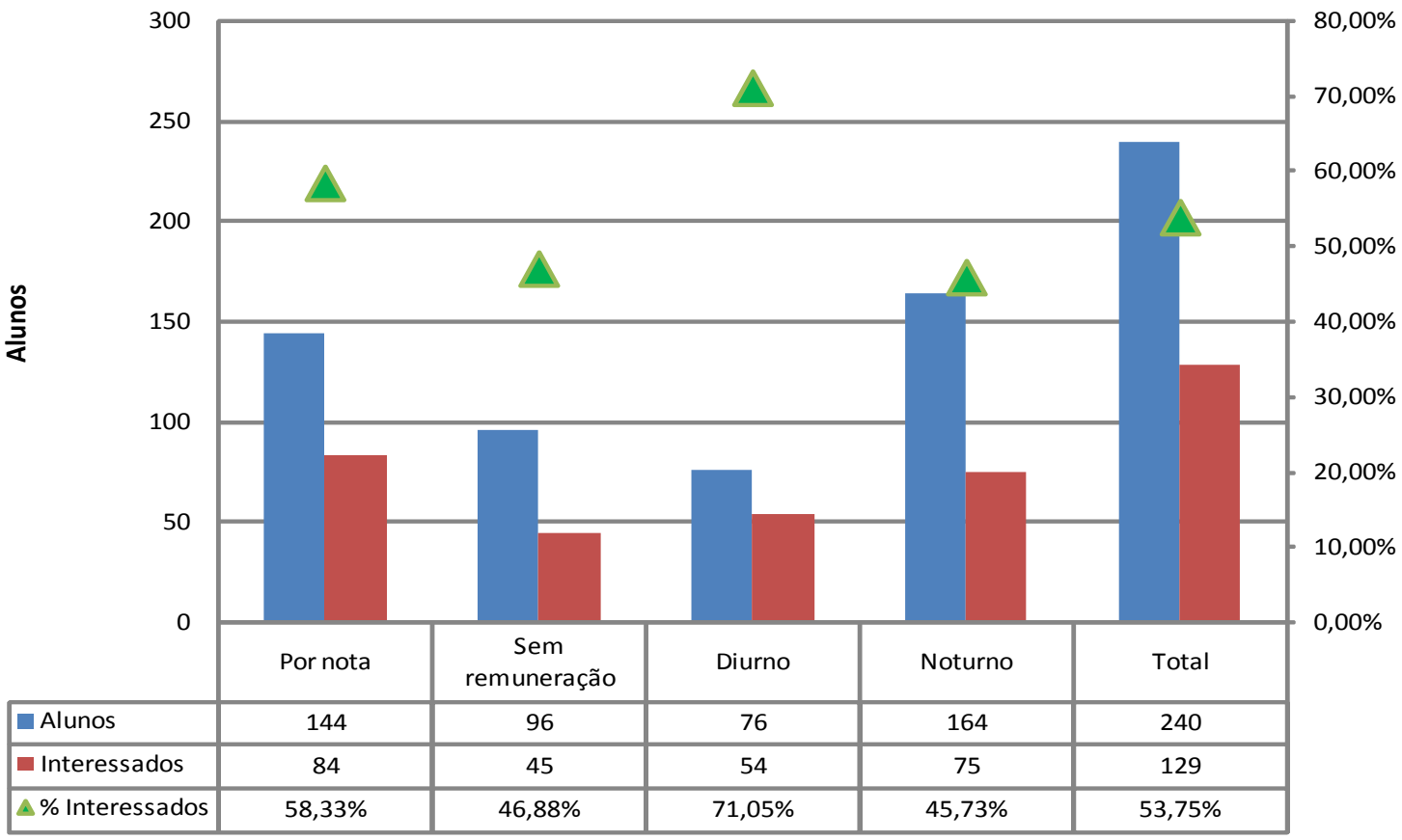

FONTE: Elaborado pelos autores.

Ao segmentarmos o grau de interesse por atividades (Tabela 3), outro aspecto interessante surge: o possível impacto do grau de dificuldade da disciplina. A disciplina onde houve maior interesse, tanto no período diurno como noturno, foi a de Macroeconomia I, tida pelos alunos do curso de Ciências Econômicas como uma das disciplinas mais difíceis da grade curricular. A conclusão é de que incentivos em notas em disciplinas mais complexas são maiores motivadores a participação do que em disciplinas menos complexas.

Um caso particular foi o da turma de Introdução ao Mercado de Capitais, com grau de interesse de 72,22\% mesmo sem remuneração. Acredita-se que esse caso ocorreu devido a pequena turma: mesmo um pequeno grupo de interessados já representaria um grande desfalque na turma, impedindo a existência de aulas; sendo assim, a atividade proposta pode ter sido utilizada como uma possível válvula de escape.

TABELA 3 - GRAU DE INTERESSE POR ATIVIDADE

\begin{tabular}{|c|c|c|c|c|c|c|}
\hline $\begin{array}{c}\text { Quanto a } \\
\text { remuneração }\end{array}$ & Disciplina & Fase & Período & Alunos & Interessados & $\begin{array}{c}\% \% \\
\text { Interessados }\end{array}$ \\
\hline Por nota & Macroeconomia I & & Diurno & 31 & 25 & $80,65 \%$ \\
\hline Sem remuneração & Introd. ao Mercado de Capitais & $8 a$ & Diurno & 18 & 13 & $72,22 \%$ \\
\hline Por nota & Mercado de Capitais & & Diurno & 27 & 16 & $59,26 \%$ \\
\hline Por nota & Macroeconomia I & & Noturno & 41 & 24 & $58,54 \%$ \\
\hline Por nota & Mercado de Capitais & & Noturno & 45 & 19 & $42,22 \%$ \\
\hline Sem remuneração & Análise de Investimentos & & Noturno & 41 & 17 & $41,46 \%$ \\
\hline$\underline{\text { Sem remuneração }}$ & Introd. ao Mercado de Capitais & & Noturno & 37 & 15 & $40,54 \%$ \\
\hline
\end{tabular}

FONTE: Elaborado pelos autores. 
O grau de abstenção (Gráfico 2), gerado pela razão entre os alunos presentes e os convocados $^{7}$, mostra menor abstenção no grupo das turmas remunerados por nota: apenas $3,70 \%$ contra 13,89\% do grupo de turmas sem remuneração. Nas turmas diurnas também houve menor abstenção: 5,13\% contra 9,80\% do noturno. Esses resultados estão de acordo com o indicador de interesse comentado anteriormente.

\section{GRÁFICO 2 - ÍNDICE DE ABSTENÇ̃̃O POR AGRUPAMENTO}

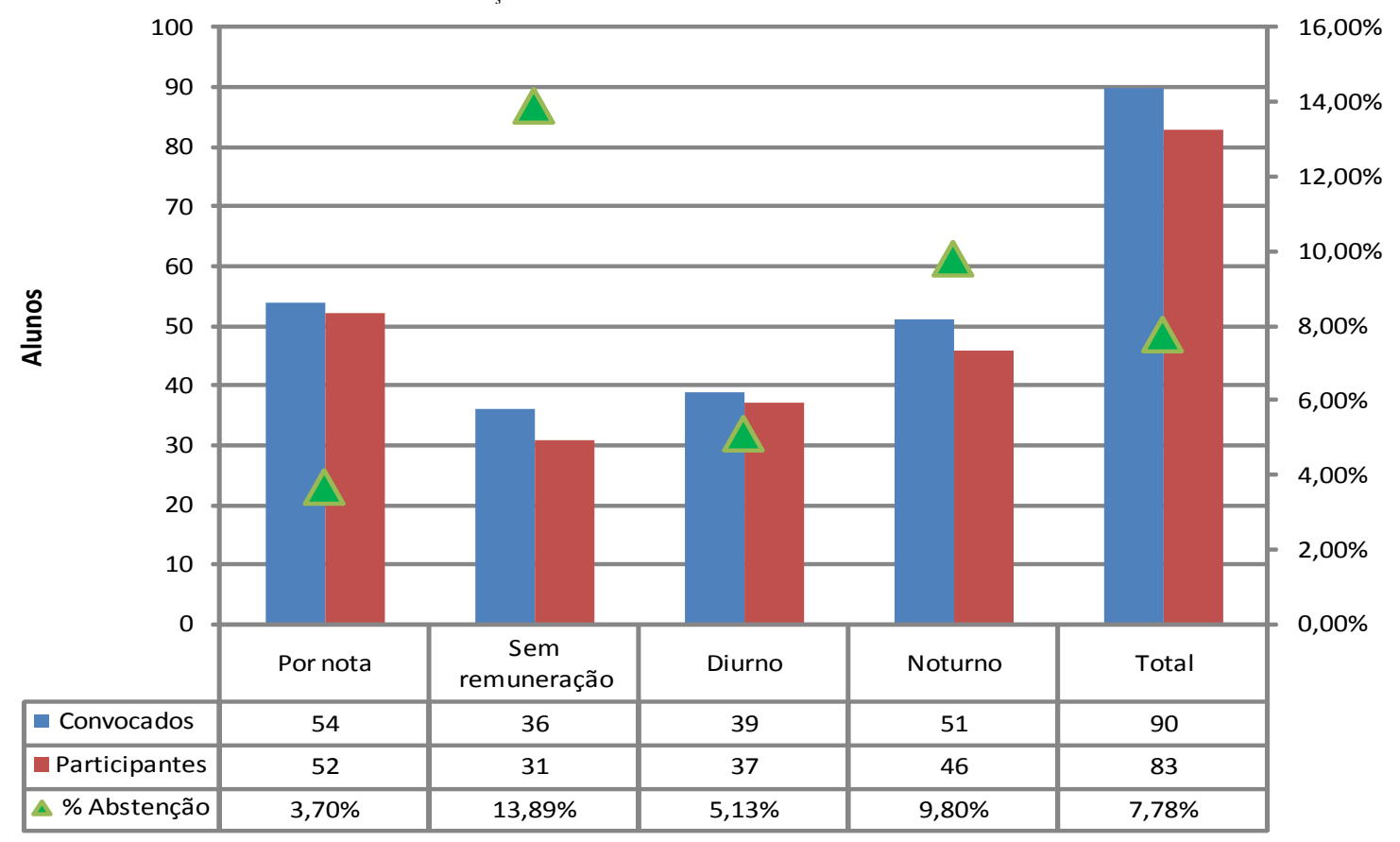

FONTE: Elaborado pelos autores.

A análise de abstenção por atividades (Tabela 4) também confirma o interesse maior na disciplina Macroeconomia I. As duas turmas com maiores índices de abstenção, Introdução ao Mercado de Capitais (9a fase) e Análise de Investimentos (6a fase), ambas com 16,67\% de abstenção, participaram da atividade sem remuneração alguma.

TABELA 4 - ÍNDICE DE ABSTENÇÃO POR ATIVIDADE

\begin{tabular}{|c|c|c|c|c|c|c|}
\hline $\begin{array}{c}\text { Quanto a } \\
\text { remuneração }\end{array}$ & Disciplina & Fase & Período & Convocados & Participantes & Abstenção \\
\hline Sem remuneração & Introd. ao Mercado de Capitais & & Noturno & 12 & 10 & $16,67 \%$ \\
\hline Sem remuneração & Análise de Investimentos & & Noturno & 12 & 10 & $16,67 \%$ \\
\hline Sem remuneração & Introd. ao Mercado de Capitais & & Diurno & 12 & 11 & $8,33 \%$ \\
\hline Por nota & Mercado de Capitais & & Noturno & 12 & 11 & $8,33 \%$ \\
\hline Por nota & Mercado de Capitais & & Diurno & 12 & 11 & $8,33 \%$ \\
\hline Por nota & Macroeconomia I & & Diurno & 15 & 15 & $0,00 \%$ \\
\hline Por nota & Macroeconomia I & & Noturno & 15 & 15 & $0,00 \%$ \\
\hline
\end{tabular}

FONTE: Elaborado pelos autores.

7 A diferença entre os alunos interessados e convocados se deu por limitação de computadores disponíveis no laboratório de informática. Nos dias das atividades das turmas de Macroeconomia I, houve maior disponibilidade de equipamentos. 
Quanto ao comportamento frente a complexidade da atividade proposta, tem-se dois pontos destacáveis. O primeiro é a existência de operações de venda abaixo do valor mínimo possível das ações, ou seja, claramente uma ação que piora o desempenho do grupo em questão em relação aos demais. Foram cinco dessas ocorrências, todas em atividades sem remuneração. Uma explicação possível seria uma falta de interesse dentro da própria atividade, mas não se pode descartar também a possibilidade de falta de compreensão das regras da atividade, apesar de ter existido uma rodada de simulação.

Houve, de forma geral, um número um pouco inferior de lances e transações por parte dos grupos remunerados por notas e diurno em relação aos grupos sem remuneração e noturno, respectivamente (Gráfico 3). Ainda assim, a diferença entre os padrões não é demasiada e não deve representar uma mudança significativa de comportamento entre os grupos.

GRÁFICO 3 - MÉDIA DE LANCES E TRANSAÇÕES POR AGRUPAMENTOS

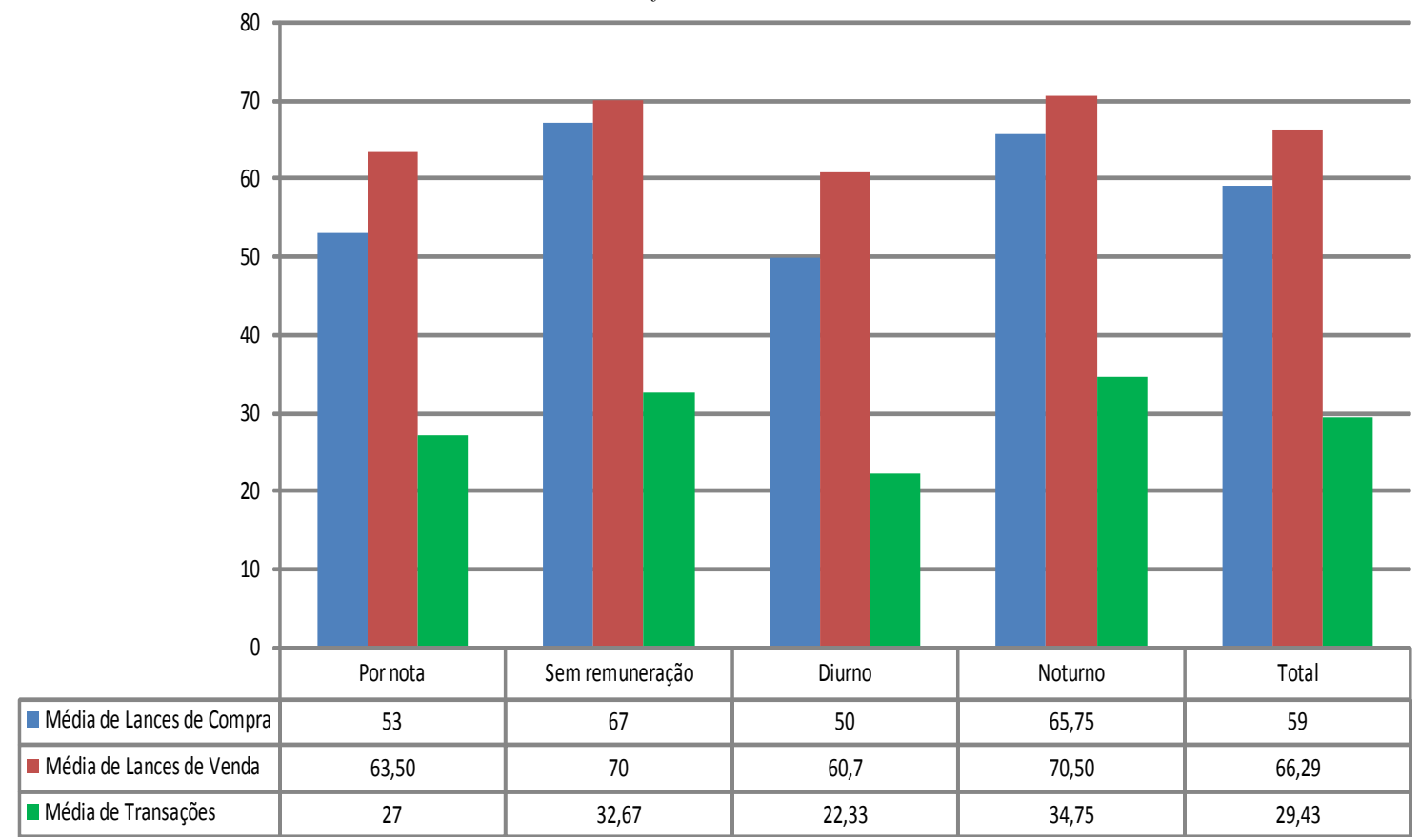

FONTE: Elaborado pelos autores.

\section{CONSIDERAÇÕES FINAIS}

Este trabalho analisou a utilização de oferta de notas em disciplinas de graduação como mecanismo de incentivo à participação dos estudantes em experimentos em economia. As atividades, que simularam um ambiente de negociação de ações, foram realizadas em diferentes cursos da Universidade Federal de Santa Catarina.

Ocorreu maior grau de interesse nas turmas onde houve incentivo na forma de notas na disciplina do que nas turmas onde buscou-se voluntários: $58,33 \%$ contra $46,88 \%$ do total de 
convidados estiveram interessados em participar. Houve também menor número de abstenção dos participantes que iriam receber notas em relação aos participantes voluntários.

Os estudantes do período diurno, de forma geral, se mostraram mais interessados em participar do que os de período noturno; os primeiros inclusive demonstraram ter maior flexibilidade nos horários para participação das atividades. Essa situação pode estar relacionada ao diferencial de perfil de alunos do período noturno e diurno: os primeiros aparentemente passam por maiores jornadas de trabalho além do curso de graduação.

Os resultados indicam que remunerar a participação e o desempenho de alunos em experimentos através de notas em disciplinas de graduação pode ser uma alternativa interessante de fomento ao desenvolvimento de atividades experimentais no Brasil. Porém, deve ser realizado com parcimônia, pois, em excesso, o mecanismo pode vir a causar viés no sistema de avaliação vigente no ambiente educacional.

\section{REFERÊNCIAS}

BERGSTROM, T.; MILLER, J. H. Instructor's manual for experiments with economic principles. McGraw-Hill, 1999.

DURHAM, Y.; MCKINNON, T.; SCHULMAN, C. Classroom experiments: not just fun and games. Economic Inquiry, v. 45, p. 162-178, 2007.

EMERSON, T. L. N.; TAYLOR, B. A. Comparing student achievment across experimental and lecture-oriented sections of a principles of microeconomics course. Southern Economic Journal. v. 70, p. 672-693, 2004.

GROVE, W. A.; WASSERMAN, T. Incentives and student learning: a natural experiment with economics problem sets. American Economic Review, v. 96, n. 2, 2006.

JACKSTADT, S. L.; JOHNSON, P.; WILSON, B. J. Promoting experimental economics in the classroom. Disponível em: < http://ssrn.com/abstract $=964747>$. 